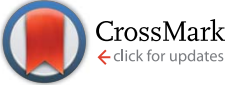

Cite this: RSC Adv., 2017, 7, 12524
Received 7th November 2016 Accepted 12th February 2017

DOI: $10.1039 / \mathrm{c} 6 \mathrm{ra} 26424 \mathrm{~g}$

rsc.li/rsc-advances

\section{Nitrogen-doped carbon materials with cubic ordered mesostructure: low-temperature autoclaving synthesis for electrochemical supercapacitor and $\mathrm{CO}_{2}$ capture}

\author{
Lei Liu, ${ }^{\text {*a }}$ Shi-Da Xu, ${ }^{a}$ Feng-Yun Wang, ${ }^{b}$ Yue-Jun Song, ${ }^{c}$ Jie Liu, ${ }^{a}$ Ze-Min Gao ${ }^{c}$ \\ and Zhong-Yong Yuan*cd
}

Nitrogen doped ordered mesoporous carbons (NOMCs) with a 3-D body-centered cubic pore structure with uniform pore size of $2.9-3.0 \mathrm{~nm}$ and high BET surface area of $583-847 \mathrm{~m}^{2} \mathrm{~g}^{-1}$ have been synthesized by means of a facile and efficient low-temperature autoclaving route under basic conditions, in which triblock copolymer F127 was used as the template, and resorcinol/hexamethylenetetramine as the carbon precursor. The effect of synthesis parameters including the autoclaving temperature and autoclaving treatment time was investigated in detail. It is found that NOMCs with cubic $\operatorname{Im} \overline{3} m$ structure can be produced at the autoclaving temperature of $60{ }^{\circ} \mathrm{C}$ and autoclaving treatment time of $\geq 2 \mathrm{~d}$. Benefiting from the unique features of high surface area, nitrogen doping, uniform and uninterrupted mesopores and rich microporosity, these NOMCs for supercapacitors exhibit high capacitance of $193 \mathrm{~F}$ $\mathrm{g}^{-1}$ at $1.0 \mathrm{~A} \mathrm{~g}^{-1}$, high rate capacity (90\% capacitance retention at $10 \mathrm{~A} \mathrm{~g}^{-1}$ ) and good cycling stability $\left(99.1 \%\right.$ capacity retention after 1000 cycles at $\left.1.0 \mathrm{~A} \mathrm{~g}^{-1}\right)$ in $6 \mathrm{M} \mathrm{KOH}$ aqueous solution and good cycling stability with specific capacitance retention over 500 cycles. Moreover, the NOMCs also show excellent $\mathrm{CO}_{2}$ capture properties with a capacity of 4.7 and $3.5 \mathrm{mmol} \mathrm{g}-1$ at 0 and $25{ }^{\circ} \mathrm{C}$, respectively. It is revealed that both textural and surface chemistry properties influenced the $\mathrm{CO}_{2}$ capture performance of the resultant NOMCs adsorbents.

\section{Introduction}

Ordered mesoporous carbons (OMCs) with highly ordered pore channels have unique characteristics, such as high surface area, chemical inertness and good electrical conductivity, thereby showing potential applications in a wide range of research fields. ${ }^{1}$ Compared to the traditional hard-templating method (nanocasting strategy) to produce OMCs, the soft-templating route based on organic-organic self-assembly is particularly more attractive due to the avoidance of many drawbacks such as multistep synthesis, consumption of time, and high cost. ${ }^{2-4}$ So far the organic-organic self-assemblies are mainly successfully applied for phenolic resins, which are often condensed by

${ }^{a}$ School of Materials Science and Engineering, Shandong University of Science and Technology, Qingdao 266590, China.E-mail: zyyuan@nankai.edu.cn; liulei@sdust. edu.cn

${ }^{b}$ College of Physics and Cultivation Base for State Key Laboratory, Qingdao University, Qingdao 266071, China

${ }^{c}$ National Institute for Advanced Materials, School of Materials Science and Engineering, Nankai University, Tianjin 300350, China

${ }^{d}$ Key Laboratory of Advanced Energy Materials Chemistry (Ministry of Education), Collaborative Innovation Center of Chemical Science and Engineering (Tianjin), Nankai University, Tianjin 300071, China acidic or basic catalysts in the presence of the surfactant template, during the formation of mesostructures. ${ }^{5-7}$ Considering commonly used catalysts $(\mathrm{NaOH}$ and $\mathrm{HCl}$ ) would result in the corrosion of the equipment and the pollution of halogenide ions, some alternative and green catalysts such as citric acid, ${ }^{8}$ amino acid, ${ }^{\mathbf{9}, 10}$ phosphonic acid $^{\mathbf{1 1}}$ and ammonia aqueous solution $^{12}$ were recently developed to catalyze the polymerization of resorcinol/formaldehyde (RF) resin, which is more flexible and convenient. Meanwhile, instead of the widely used precursor of RF resin, some other carbon precursors were also developed. ${ }^{\mathbf{1 3}}$ Through self-polymerization of dopamine and spontaneous coassembly of diblock copolymer micelles, nitrogen-doped mesoporous carbon spheres with large pores of $\sim 16 \mathrm{~nm}$ has been obtained. ${ }^{1}$ Hexamethylenetetramine (HMT) was demonstrated to be a release source of formaldehyde towards the selfassembly synthesis of RF-based OMCs through employing resorcinol and HMT as precursors. ${ }^{14}$ However, the resultant carbon materials have only a common 2-D hexagonal mesostructure. And the hydrothermal synthesis was performed under the relative high temperature of $100-220{ }^{\circ} \mathrm{C}$.

Despite the great progress in the synthesis of OMCs, there are only a few reports on the syntheses of OMCs with 3-D cubic structure based on RF resin and $\mathrm{F} 127 .{ }^{15}$ Recently, Liu et al. 
reported the preparation of OMCs with $\operatorname{Im} \overline{3} m$ structure through aqueous self-assembly of RF resin and F127. ${ }^{12}$ They demonstrated that the optimal reaction temperature for the formation of ordered mesostructures was $\sim 80{ }^{\circ} \mathrm{C}$, whereas no product could be obtained below $70{ }^{\circ} \mathrm{C}$. Additionally, the obtained carbons had large particle size of approximately 5-15 $\mu \mathrm{m}$, which was disadvantage for some applications, such as supercapacitor electrodes materials, due to their inherent long diffusion path way. ${ }^{16,17}$

In addition, previous studies have revealed that doping nitrogen into the carbon matrix can enhance the electrical, and structural characteristics of carbons, ${ }^{18-21}$ endowing them with excellent performance in supercapacitors ${ }^{18-20}$ Herein, nitrogen doped OMCs (NOMCs) with body-centered cubic structure $(\operatorname{Im} \overline{3} m)$ were synthesized through a low-temperature autoclaving (LTA) route at $60^{\circ} \mathrm{C}$ in the presence of resorcinol and HMT as carbon precursors under basic conditions. A detailed examination of synthesis parameters including the autoclaving temperature and time was carried out. Their potential applications as electrodes materials for supercapacitors and as adsorbents for $\mathrm{CO}_{2}$ capture were evaluated. The $900{ }^{\circ} \mathrm{C}$-carbonized samples exhibit high specific capacitance of up to $193 \mathrm{~F} \mathrm{~g}^{-1}$ at $1.0 \mathrm{~A} \mathrm{~g}^{-1}$ in $6 \mathrm{M} \mathrm{KOH}$ aqueous solution and display a good rate performance due to the uninterrupted mesoporous channels that favor rapid ion diffusion while a proper number of micropores offer large surface area. The $\mathrm{CO}_{2}$ adsorption capacities reach 4.7 and $3.54 \mathrm{mmol} \mathrm{g}^{-1}$ at 0 and $25{ }^{\circ} \mathrm{C}$, respectively.

\section{Experimental section}

\subsection{Synthesis}

NOMCs were synthesized by a LTA method. In a typical synthesis, $1.1 \mathrm{~g}$ of resorcinol and $2.5 \mathrm{~g}$ of $\mathrm{F} 127$ were dissolved in $50 \mathrm{~mL}$ of water at room temperature, followed by the addition of $0.701 \mathrm{~g}$ of HMT. After being stirred for $30 \mathrm{~min}, 1.8 \mathrm{~g}$ of $37 \mathrm{wt} \%$ ammonia solution was added dropwise under tempestuously stirring. The reaction mixture was further stirred for another one hour, and was then transferred to a Teflon-lined autoclave and heated at $60{ }^{\circ} \mathrm{C}$ for $1-4 \mathrm{~d}$. The black solid product was recovered by filtration, washed with water and dried in an oven at $100{ }^{\circ} \mathrm{C}$. Carbonization was carried out in a tubular furnace under an inert atmosphere ( $\mathrm{N}_{2}$ flow) with the heating rate of $1{ }^{\circ} \mathrm{C} \mathrm{min}{ }^{-1}$, and then keeping the temperature for $2 \mathrm{~h}$. The final product was denoted as HMC- $x-y$ d, wherein $x$ represents the autoclaving temperature, $y$ refers the autoclaving treatment time (d in unit).

\subsection{Characterization}

Powder X-ray diffraction (XRD) pattern was performed on a Rigaku D/max-2500 diffractometer, with $\mathrm{Cu} \mathrm{K} \alpha$ radiation $(\lambda=$ $1.5406 \AA$ ) at a scanning rate of $0.01^{\circ} \mathrm{s}^{-1}$. Transmission electron microscopy (TEM) measurements were recorded using a FEI Tecnai F20 microscope at $200 \mathrm{kV}$. All samples subjected to TEM measurements were ultrasonically dispersed in ethanol and drop-casted onto copper grids covered with carbon film.
Nitrogen adsorption and desorption isotherms were measured on a Quantachrome EVO sorption analyzer at $77 \mathrm{~K}$. Before measurements, the samples were degassed in a vacuum at $200{ }^{\circ} \mathrm{C}$ for at least $6 \mathrm{~h}$. The Brunauer-Emmett-Teller (BET) method was utilized to calculate the specific surface areas $\left(S_{\mathrm{BET}}\right)$, the pore size distributions were derived from the adsorption branches of isotherms using density functional theory (DFT) method, and the total pore volumes $\left(V_{\text {total }}\right)$ were estimated from the adsorbed amount at a relative pressure $P / P_{0}$ of 0.980 . Fourier transform infrared (FT-IR) spectra were collected on a Nicolet Fourier spectrophotometer, using $\mathrm{KBr}$ pellets of the solid samples. $\mathrm{CO}_{2}$ sorption isotherms were measured at different desired temperatures using a QuantachromeAutosorb-1MP instrument. Prior to each adsorption measurement, the samples were degassed at $250{ }^{\circ} \mathrm{C}$ for $8 \mathrm{~h}$ to remove the guest molecules from pores.

\subsection{Electrochemical measurements}

Electrochemical measurements were conducted with a threeelectrode electrochemical cell with $6 \mathrm{M} \mathrm{KOH}$ aqueous electrolyte on IM6 and ZENNIUM electrochemical workstation. The standard three-electrode electrochemical cell was fabricated using platinum sheet as the counter electrode, and $\mathrm{Ag} / \mathrm{AgCl}$ as the reference electrode. The working electrodes were prepared by mixing the active material, acetylene black and polytetrafluoroethylene (PTFE) binder with a weight ratio of $85: 10: 5$. After coating the above slurry onto the nickel foam current collector $(1 \mathrm{~cm} \times 1 \mathrm{~cm})$, the electrodes were dried at $70{ }^{\circ} \mathrm{C}$ overnight before pressing under a pressure of $10 \mathrm{MPa}$. The cyclic voltammetry $(\mathrm{CV})$ voltage scanning range was from -1.0 to $0 \mathrm{~V}$, with the scan rate from 5 to $100 \mathrm{mV} \mathrm{s}^{-1}$. The electrochemical impedance spectroscopy (EIS) was conducted at an amplitude of $10 \mathrm{mV}$ in the frequency range from $100 \mathrm{kHz}$ to 1 mHz. Galvanostatic charge-discharge cycling was also performed in the 0 and $-1.0 \mathrm{~V}$ range in the aqueous medium at current densities in the $1.0-10 \mathrm{~A} \mathrm{~g}^{-1}$ range based on the active mass of a single electrode. The specific gravimetric capacitance of a single electrode $\left(\mathrm{F} \mathrm{g}^{-1}\right)$ determined from the galvanostatic cycles was calculated by means of the formula:

$$
C_{\mathrm{g}}=\frac{I \Delta t}{m \Delta V}
$$

where $I, \Delta t, \Delta V$, and $m$ are the applied current, discharge time, voltage change, and the mass of active material, respectively.

\section{Results and discussion}

\subsection{Material synthesis and characterization}

NOMCs with body-centered cubic structure are produced under LTA conditions (Fig. 1). After all reactants are dissolved, the resorcinol molecules with high hydroxyl density can strongly interact with the PEO segments of F127 through the enhanced hydrogen-bonding interactions. It has been demonstrated that under atmospheric pressure, HMT was unable to hydrolyze to form ammonia and formaldehyde below $70{ }^{\circ} \mathrm{C}$ in a non-acidic aqueous solution. ${ }^{22}$ However, under autoclaving conditions, the autogenous pressure plays an important role to promote 


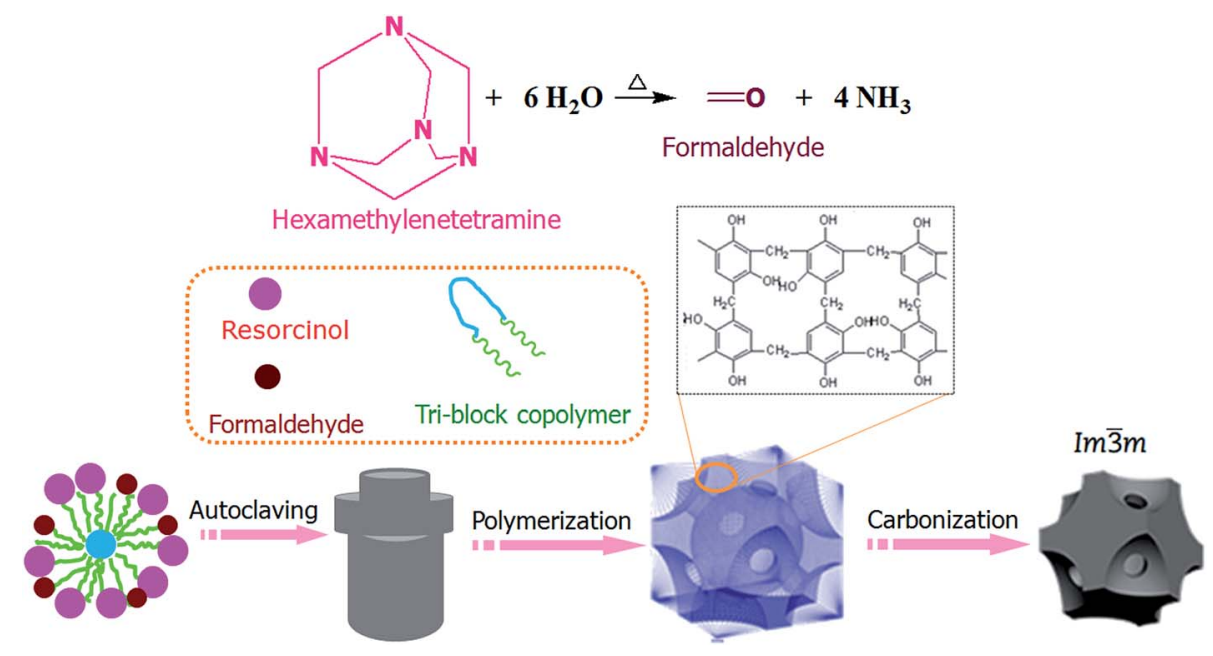

Fig. 1 A schematic illustration depicting the synthesis route for NOMCs with body-centered cubic structure.

HMT hydrolysis gradually into formaldehyde and ammonia at temperature as low as $60{ }^{\circ} \mathrm{C}$, and enhance the interaction between the molecules and induce the fast polymerization rate.

Fig. 2 shows the low-angle XRD patterns of the carbon materials obtained at different autoclaving temperatures. A sharp and narrow diffraction peak at $2 \theta$ value of $0.69^{\circ}$ is observed on HMC-60-2d sample which is obtained at autoclaving temperature of $60{ }^{\circ} \mathrm{C}$, indicating the ordered mesostructure. While the autoclaving temperature increases to 80$100{ }^{\circ} \mathrm{C}$, the obtained samples shows no diffraction peak, implying their disordered mesostructure, which is probably due to too fast reaction rate under autoclaving conditions with the temperature above $80^{\circ} \mathrm{C}$.

Since OMCs can be obtained at autoclaving temperature of $60{ }^{\circ} \mathrm{C}$, the effect of autoclaving treatment time on the porous structure of the resultant NOMCs was also investigated. The low-angle XRD patterns of NOMCs obtained under autoclaving treatment times of 1-4 d are shown in Fig. 3. One wide and poorly resolved reflection peak with $2 \theta$ value of $0.60^{\circ}$ is observed

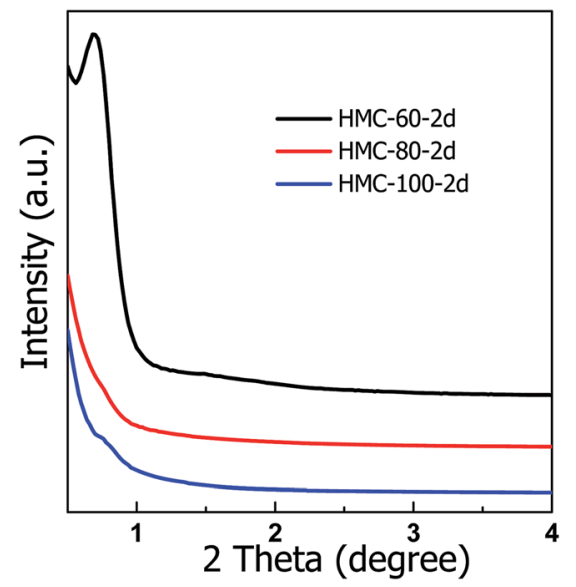

Fig. 2 Low-angle XRD patterns of HMC-x-2d samples obtained at different the autoclaving temperature. for HMC-60-1d. While autoclaving treatment time for 2 days, the reflection peak of HMC-60-2d becomes sharp, suggesting its regularity is superior to that of HMC-60-1d (Fig. 3b). HMC-60-3d represents three well-resolved diffraction peaks with $2 \theta$ value of $0.96,1.37$, and $1.71^{\circ}$ (Fig. 3c), which can be indexed as (110), (200) and (211) Bragg reflections, respectively and assigned to the body-centered cubic $\operatorname{Im} \overline{3} m$ symmetry. ${ }^{23}$ The $\operatorname{Im} \overline{3} m$ symmetry can be further confirmed by TEM images as shown in Fig. 4 . High-quality and large-domain regularity arrangement of porous structure is clearly observed along the (110) and (111) directions (Fig. 4a and b). The pore size and pore wall thickness of HMC-60-3d estimated from the TEM images are 2.9 and $8.6 \mathrm{~nm}$, respectively, being in good agreement with the values determined from the XRD results. The cell parameter of HMC$60-3 \mathrm{~d}$ is calculated to be $13.3 \mathrm{~nm}$, while that of HMC- $60-4 \mathrm{~d}$ is $13.0 \mathrm{~nm}$ (Table 1). Compared the samples with different autoclaving time (Table 1), it is clearly revealed that the longer reaction time may enhance the interaction between $\mathrm{RF}$ resin

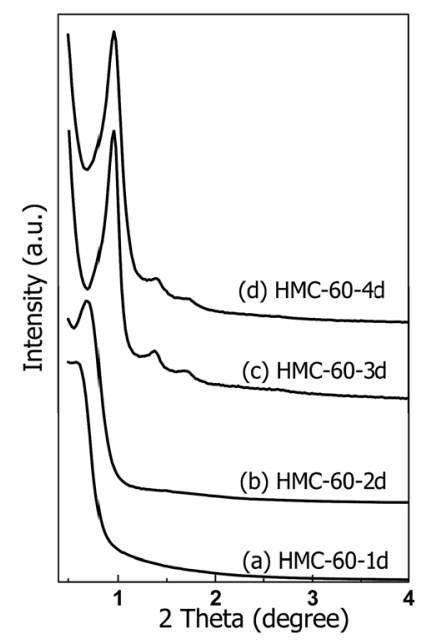

Fig. 3 Low-angle XRD patterns of HMC-60-yd samples obtained at different autoclaving time. 

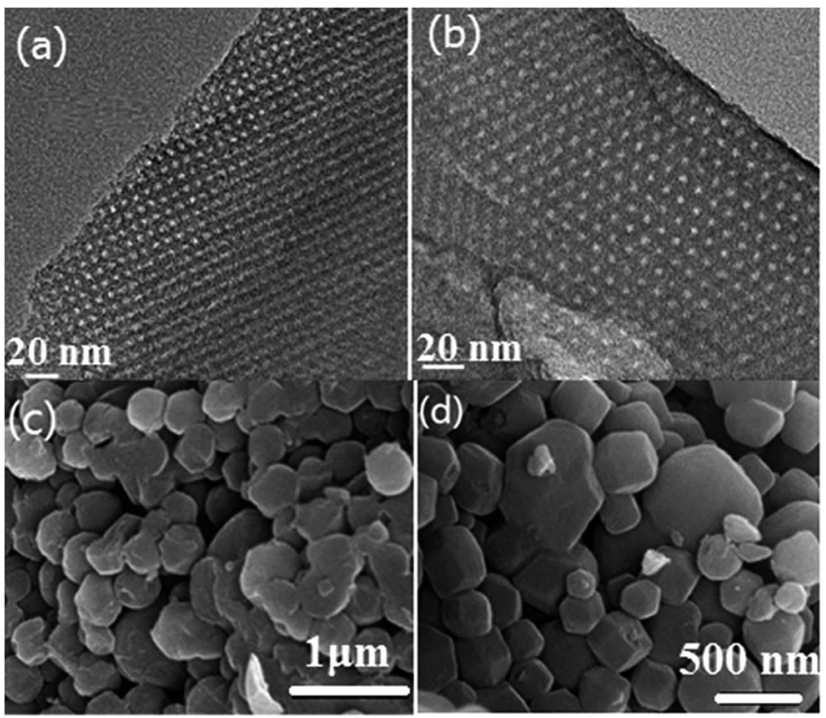

Fig. 4 TEM images of HMC-60-3d viewed along [110] (a) and [111] (b) directions. SEM image of as-made HMC-60-3d (c) and carbonized HMC $-60-3 d(d)$.

and the polyethylene oxide (PEO) segments of F127 and improve the cross-linking degree. The SEM images (Fig. $4 \mathrm{c}$ and d) show that HMC-60-3d is composed of irregularly polyhedral particles with the size of $0.3-1.5 \mu \mathrm{m}$.

The $\mathrm{N}_{2}$ sorption isotherms (Fig. 5) illustrate that carbonized HMC-60-yd materials have typical type-IV curves with an obvious $\mathrm{H}_{2}$-type hysteresis loop and a sharp capillary condensation step in the $P / P_{0}$ range from 0.4 to 0.7 , corresponding to a 3-D caged mesostructure with a narrow pore size distribution. ${ }^{24,25}$ The HMC-60-2d sample shows capillary condensation at relative pressures of $0.4-0.65$, and a narrow pore size distribution with a mean value of $3.1 \mathrm{~nm}$ (Fig. $5 \mathrm{~b}$ ) can be calculated by the NLDFT model. After the increase of autoclaving time to $3 \mathrm{~d}$, HMC-60-3d exhibits a capillary condensation with a shift to low relative pressure, and the pore size is reduced to $3.0 \mathrm{~nm}$, while the BET surface are and pore volume calculated to $580 \mathrm{~m}^{2} \mathrm{~g}^{-1}$ and $0.31 \mathrm{~cm}^{3} \mathrm{~g}^{-1}$, respectively. The $t$-plot calculation reveals that the micropore volume of HMC-60-yd enlarges with increasing autoclaving time (Table 1). The longer the autoclaving treatment time, the stronger interaction between F127 and RF resin. The embedded PEO segments of F127 could makes more disfigurement in the pore wall of the final products ${ }^{23}$ which can introduce more microporosity in the carbons after removal of templates.

Carbonizing the as-made HMC-60-3d sample at $450-900{ }^{\circ} \mathrm{C}$ under $\mathrm{N}_{2}$ atmosphere gives a resolved XRD pattern (Fig. 6), which suggests that highly ordered cubic mesostructure $(\operatorname{Im} \overline{3} m)$ is obtained. The calculation from XRD measurements reflects large unit cell parameters $(a)$ of $15.1 \mathrm{~nm}$ for HMC-60-3d (450). With further increasing the calcinations temperature to $600{ }^{\circ} \mathrm{C}$, three resolved diffraction peaks (Fig. 6b) assigned to the $\operatorname{Im} \overline{3} m$ symmetry can be observed, but with a shift to higher $2 \theta$ degree, accompanied by the decrease of the unit cell parameter to $13.3 \mathrm{~nm}$. When the carbonization temperature is elevated to 800 and even $900{ }^{\circ} \mathrm{C}$ (see Fig. $6 \mathrm{c}$ and d), the XRD patterns still show three distinct diffraction peaks assigned to the $\operatorname{Im} \overline{3} m$ symmetry with unit cell parameters of 12.7 and $12.2 \mathrm{~nm}$, respectively (Table 1). This indicates that HMC-60-3d is highly thermally stable.

Fig. 7 depicts the $\mathrm{N}_{2}$ sorption isotherms of the HMC-60-3d samples carbonized at different temperatures. Typical type-IV curves with a clear condensation step at $P / P_{0}=0.2-0.7$ are observed for HMC-60-3d(450), implying the mesoporous characteristic. The adsorption and desorption isotherms of HMC$60-3 \mathrm{~d}(450)$ are not closed, attributed to its polymeric framework. HMC-60-3d(450) exhibits a large pore size of $3.4 \mathrm{~nm}$, and a high BET surface area of $348 \mathrm{~m}^{2} \mathrm{~g}^{-1}$. The 800 and $900{ }^{\circ} \mathrm{C}-$ carbonized samples also yield typical type-IV isotherms with capillary condensation appeared at lower relative pressures, consistent with the reduced pore sizes (Table 1). Narrow pore size distributions are observed with mean pore size of $2.9 \mathrm{~nm}$ for both HMC-60-3d(800) and HMC-60-3d(900) (Fig. 7b), indicative of high thermal stability, which is consistent with the XRD results.

X-ray photoelectron spectroscopy (XPS) was performed to analyze the chemical state of the NOMCs samples carbonized at different temperatures. Three obvious peaks at 285, 400, and $530 \mathrm{eV}$, corresponding to $\mathrm{C} 1 \mathrm{~s}, \mathrm{~N} 1 \mathrm{~s}$, and $\mathrm{O} 1 \mathrm{~s}$, are observed (Fig. 8a), indicating the presence of $\mathrm{C}, \mathrm{N}$, and $\mathrm{O}$ elements. The

Table 1 Textural and structural properties of the synthesized NOMCs

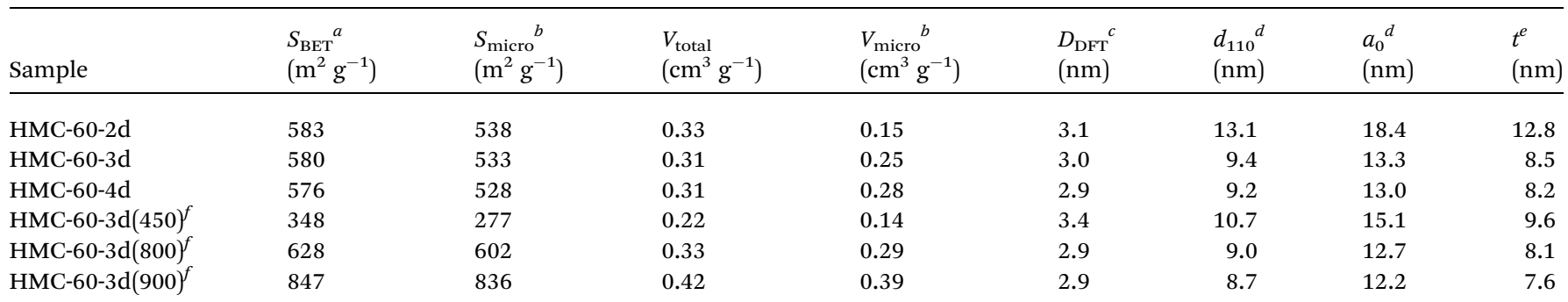

${ }^{a}$ The BET surface area, $S_{\mathrm{BET}}$, was calculated using adsorption data in a relatively pressure range $P / P_{0}=0.05-0.24 .^{b}$ The micropore volume $V_{\text {micro }}$ and micropore surface area $S_{\text {micro, }}$, were estimated from $t$-plot method. ${ }^{c}$ The pore size, $D_{\mathrm{DFT}}$, was obtained from the maxima of the pore size distribution curve calculated by the NLDFT model. ${ }^{d}$ The $d$-spacing of the 110 diffraction $d(110)$ and cell parameter $a_{0}$ were obtained from the small-angle XRD patterns by $a_{0}=\sqrt{ } 2 d(110) .{ }^{e}$ Wall thickness was calculated as thickness $t=\sqrt{ } 3 a_{0} / 2-D_{\text {DFT }}{ }^{f}$ The numbers in the parentheses represent the carbonization temperature. 

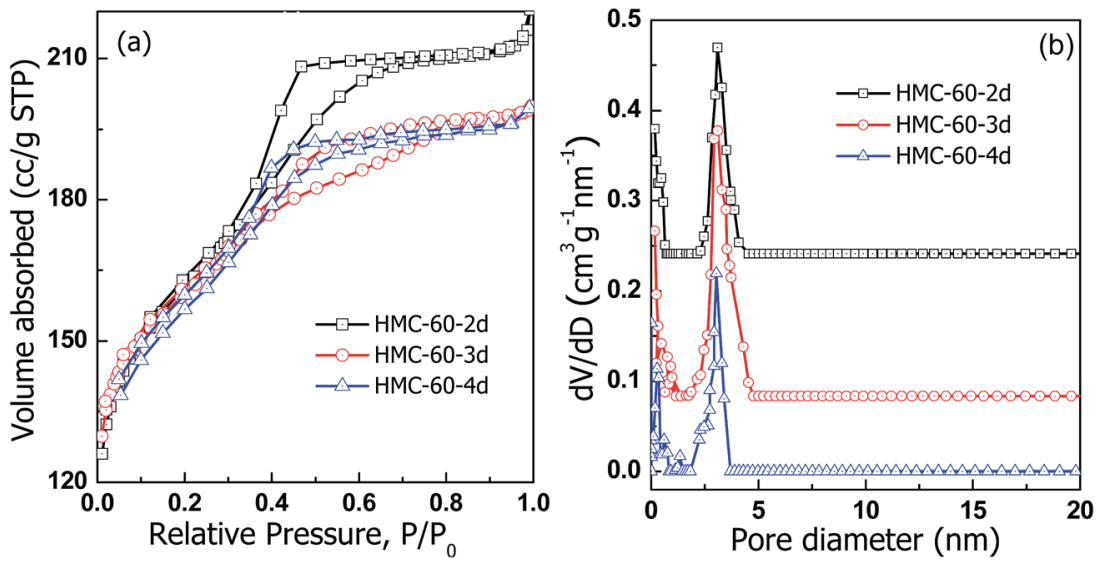

Fig. 5 Nitrogen sorption isotherms and the corresponding pore size distribution curves of the HMC-60-yd carbons obtained at different autoclaving time. The $\mathrm{dV} / \mathrm{d} D$ value was shifted by 0.08 and 0.24 for the samples of HMC-60-3d and HMC-60-2d, respectively.

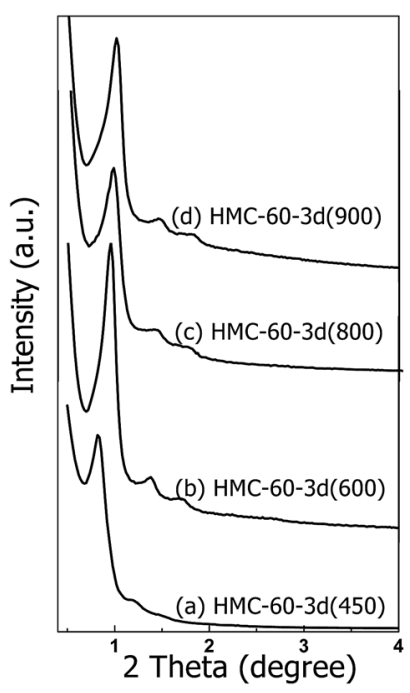

Fig. 6 Low-angle XRD patterns of the HMC-60-3d carbons carbonized at different temperatures. high resolution XPS spectrum of $\mathrm{N}$ 1s spectra (Fig. 8b-d) can be deconvoluted into four type nitrogen functional groups: pyrrolic $\mathrm{N}(398.6 \mathrm{eV})$, pyrrolic $\mathrm{N}$ (400 eV), graphitic $\mathrm{N}(400.9 \mathrm{eV})$, and pyridine N-oxide (403 eV), respectively. ${ }^{26}$ The relative nitrogen content firstly increased from 1.39 to 2.10 at $\%$, and then decreased to 1.54 at $\%$ when the carbonization temperature elevated from 600 to $900{ }^{\circ} \mathrm{C}$. The initial increment of nitrogen amount is ascribed to the substitution of most of active oxygen sites by the nitrogen atoms as the carbonization temperature increased from 600 to $800{ }^{\circ} \mathrm{C}^{27}$ Therefore, it can be concluded that by using this efficient LTA method, NOMCs with highly ordered cubic $\operatorname{Im} \overline{3} m$ mesostructure and functionalization can be easily generated, which was hardly achieved in the previous works.

\subsection{Electrodes for supercapacitors}

To explore the potential applications of the NOMCs, the samples carbonized at different temperatures were fabricated into electrodes. The CV response of the NOMCs carried out at
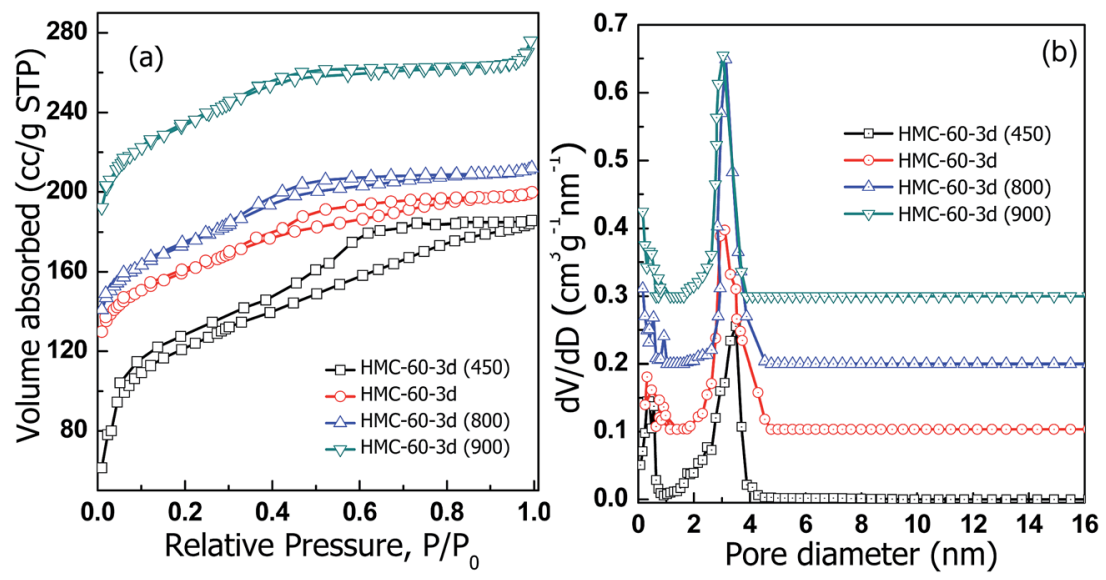

Fig. 7 Nitrogen sorption isotherms and the corresponding pore size distribution curves of the HMC-60-3d carbons carbonized at different temperatures. The $d V / d D$ value was shifted by $0.10,0.20$ and 0.30 for the samples of HMC-60-3d, HMC-60-3d(800) and HMC-60-3d(900), respectively. 

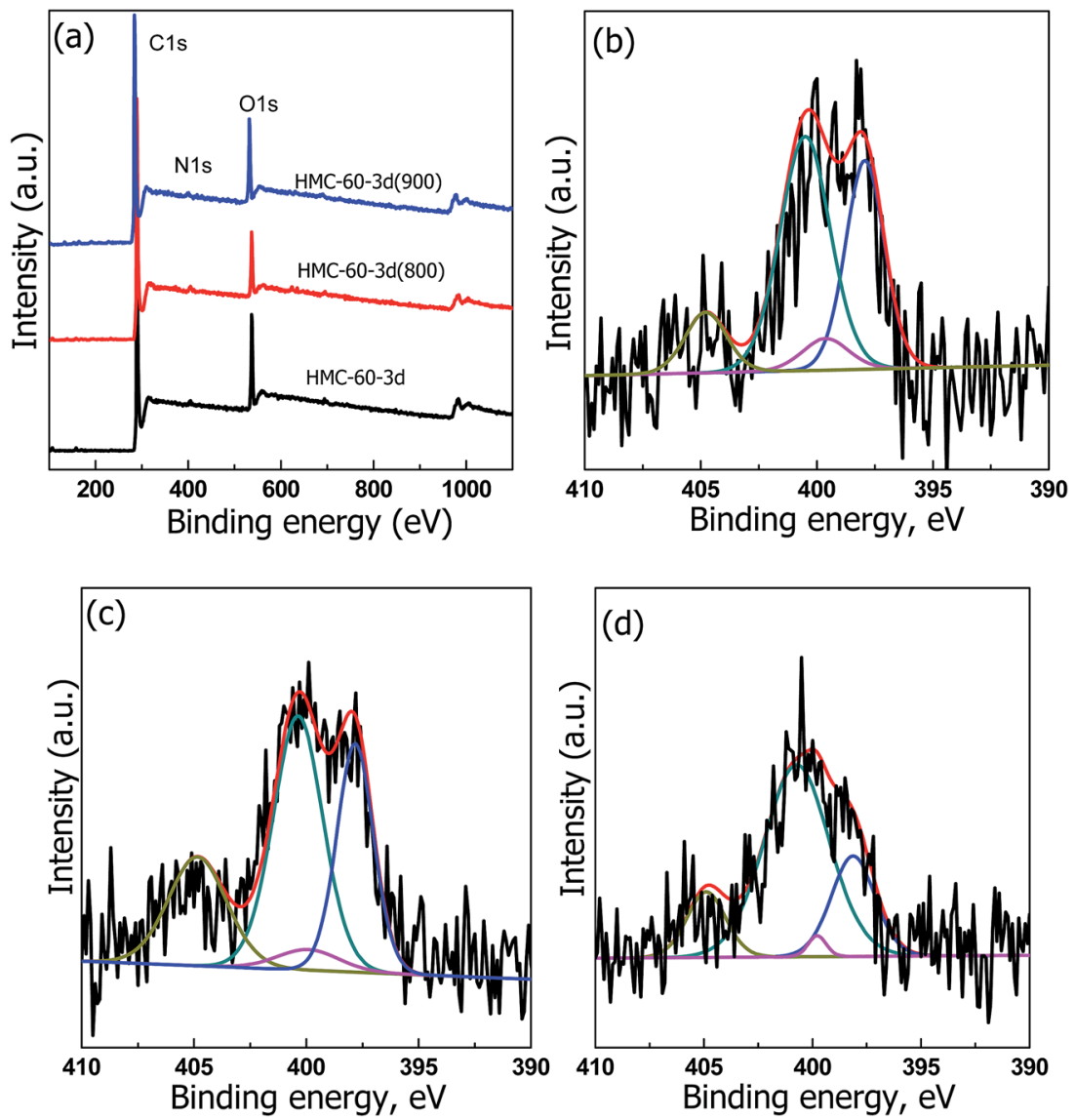

Fig. 8 (a) X-ray photoelectron survey spectra. N 1s spectra of (b) HMC-60-3d, (c) HMC-60-3d(800), (d) HMC-60-3d(900).

scan rate of $20 \mathrm{mV} \mathrm{s}^{-1}$ between 0 and $-1.0 \mathrm{~V}$ in $6 \mathrm{M} \mathrm{KOH}$ solution using a three-electrode system is shown in Fig. 9. For all samples, CV curves retain a rectangular shape over a wide range of scan rates. No leaf-like current response appeared even at the scan rate of $100 \mathrm{mV} \mathrm{s}^{-1}$ (as shown in Fig. 9b), demonstrating fast electron transfer and ion diffusion/adsorption. ${ }^{28}$ However, compared with the samples carbonized at the temperature higher than $600{ }^{\circ} \mathrm{C}$, it is clear that the HMC-60$3 \mathrm{~d}(450)$ electrodes exhibit a much smaller $\mathrm{CV}$ area, indicating a lower specific capacitance, which may be due to its low surface area and microporosity as well as its polymeric framework. The capacitance calculated from CV curves of HMC-60-3d, HMC-60$3 \mathrm{~d}(800)$, and HMC-60-3d(900) electrode is 107, 138, and $176 \mathrm{~F}$ $\mathrm{g}^{-1}$ at $20 \mathrm{mV} \mathrm{s}^{-1}$, respectively. The highest capacitance of HMC60-3d(900) may be related to the moderate amount of nitrogen and its highest microporous surface area.

Consistent with the CV results, all galvanostatic charge/ discharge curves show symmetric features with a fairly linear slope. As shown in Fig. 10, the unobvious electrode-potential drops of all curves are small, indicating a low overall resistance of the obtained NOMCs. At current density of $1.0 \mathrm{~A} \mathrm{~g}^{-1}$, the specific capacitance values of HMC-60-3d, HMC-60-3d(800) and HMC-60-3d(900), estimated from charge-discharge curves, are 133, 183 and $193 \mathrm{~F} \mathrm{~g}^{-1}$, respectively. It is clearly seen that the specific capacitance increases with the carbonization temperature and the surface area of NOMCs. The specific capacitance value of HMC-60-3d(900) electrode is comparable with NOMCs synthesized by an evaporation induced self-assembly method (213 $\mathrm{F} \mathrm{g}^{-1}$ at $\left.0.5 \mathrm{~A} \mathrm{~g}^{-1}\right)^{29}$ or templated from SBA-15 $\left(230 \mathrm{~F} \mathrm{~g}^{-1}\right.$ at $0.5 \mathrm{~A}$ $\left.\mathrm{g}^{-1}\right),{ }^{30}$ but is superior to that of $\mathrm{N}$ - and O-doped hollow carbon spheres $\left(160 \mathrm{~F} \mathrm{~g}^{-1} \text { at } 1.0 \mathrm{~A} \mathrm{~g}^{-1}\right)^{31}$ and some reported yolk-shell carbon spheres $\left(178 \mathrm{~F} \mathrm{~g}^{-1}\right.$ at $\left.1 \mathrm{~A} \mathrm{~g}^{-1}\right) .^{32,33}$ Even at high current density of $10 \mathrm{Ag}^{-1}$, no obvious voltage drop at the current switches is observed, indicating a quite low resistance of the electrode. It is noteworthy that the HMC-60-3d(900) electrode still exhibits relative high capacitance of $174 \mathrm{~F} \mathrm{~g}^{-1}$ at current density of $10 \mathrm{~A} \mathrm{~g}^{-1}$ with the retention of $90 \%$, which is much higher than some other the recently used carbons for high performance supercapacitors. For example, $45 \%$ retention and $150 \mathrm{~F} \mathrm{~g}^{-1}$ for hierarchically porous carbon materials at a current density of $2 \mathrm{~A} \mathrm{~g}^{-1},{ }^{34} 43 \%$ retention and $90 \mathrm{~F} \mathrm{~g}^{-1}$ for nitrogen- and oxygen-doped hollow carbon spheres at $5 \mathrm{~A} \mathrm{~g}^{-1},{ }^{24} 85 \%$ retention for mesoporous nitrogen-doped carbon at $10 \mathrm{~A} \mathrm{~g}^{-1} .^{30}$ The superior electrochemical performance of HMC-60-3d(900) for EDLCs can be attributed to its unique structural features, i.e. the high surface area, welldeveloped mesopores and micropores and nitrogen doping. A high specific surface area leads to a high electrode-electrolyte interface for electric double layer formation, while the uninterrupted mesopores provide low-resistant pathways for ion diffusion, the micropores strengthen the charge accommodation. ${ }^{28,35,36}$ Furthermore, the nitrogen functional groups bring in pseudocapacitive interactions and help the electron transfer through the 

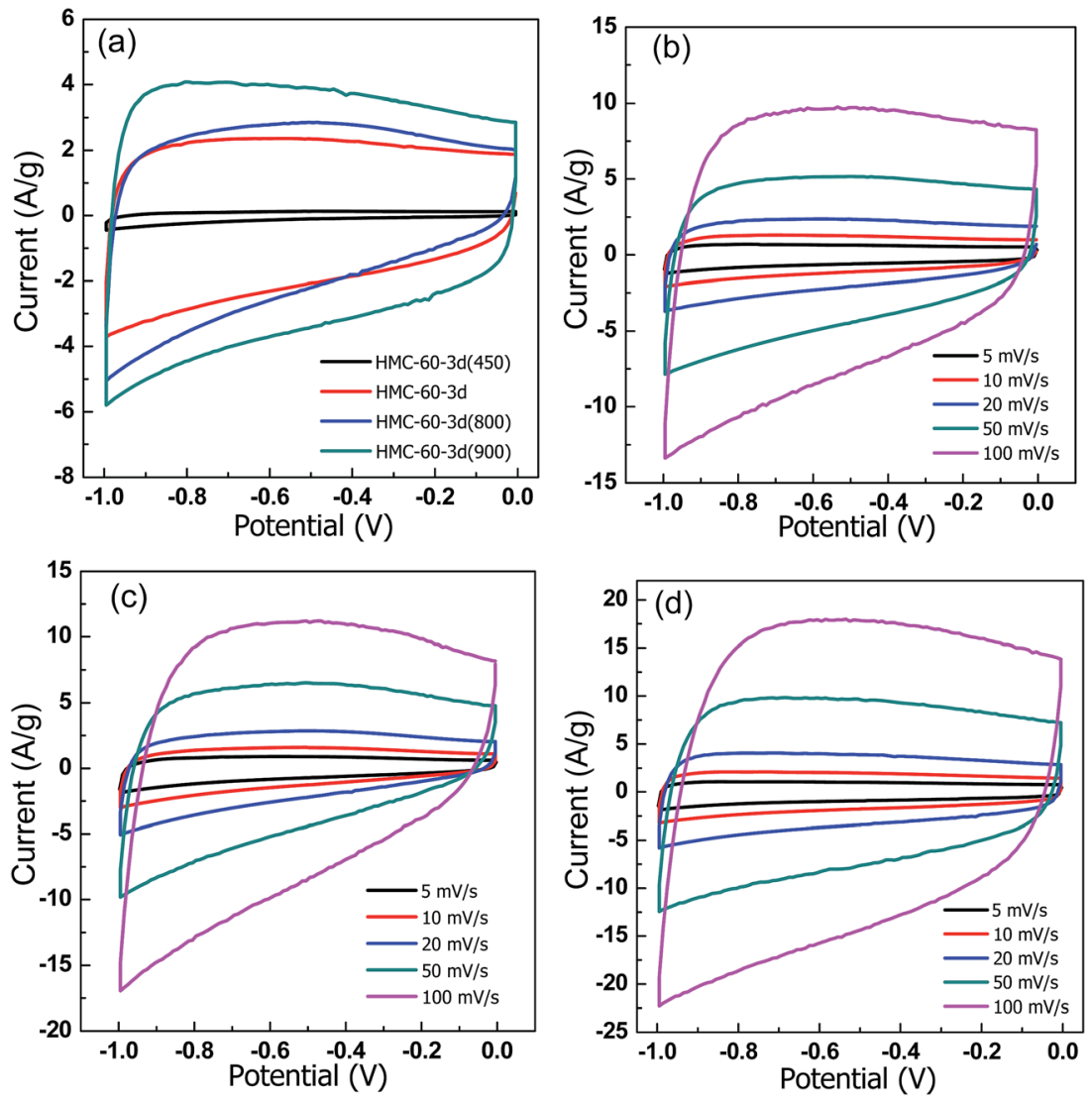

Fig. $9 \mathrm{CV}$ curves of all samples at $20 \mathrm{mV} \mathrm{s}^{-1}$. (a) CV curves at different scan rates for (b) HMC-60-3d, (c) HMC-60-3d(800) and (d) HMC-603d(900). Electrolyte: $6 \mathrm{M} \mathrm{KOH}$.
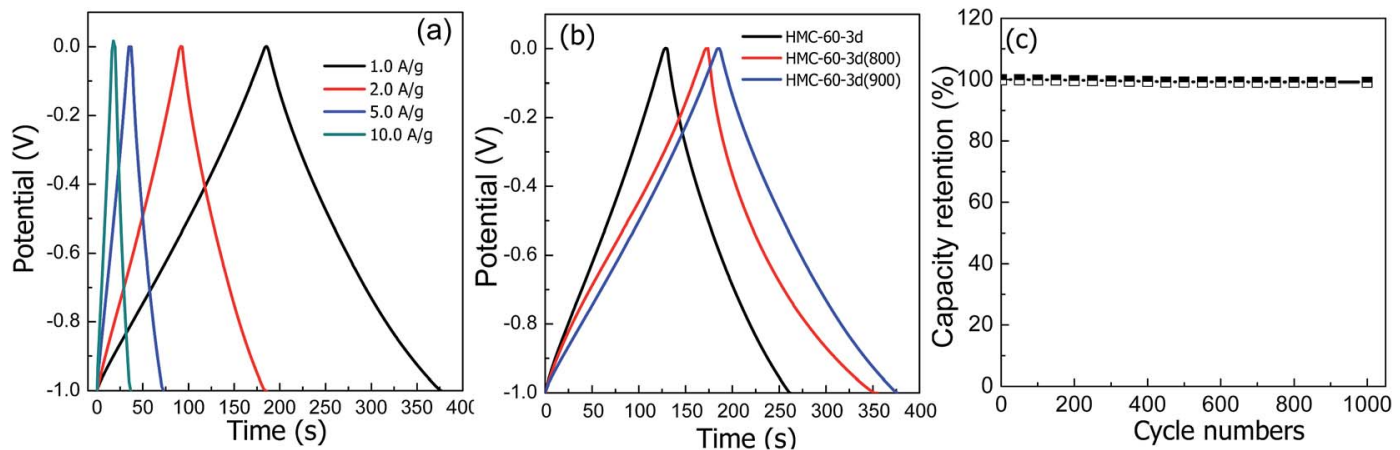

Fig. 10 Galvanostatic charge-discharge voltage profiles for HMC-60-3d(900) at different current densities (a) and different carbons at 1.0 A $\mathrm{g}^{-1}$ (b) and the capacitance of carbon materials versus the number of charge/discharge cycles (c).

carbons. In addition, small size of the NOMCs particle also plays an important role to the high capacitances. It is evident that the electrolyte solution can penetrate a larger faction of the pore structure in case of smaller particles, resulting in higher capacitance. ${ }^{37}$ To investigated the cycling stability, 1000 cycles of charge/ discharge cycles were performed at current density of $1.0 \mathrm{~A} \mathrm{~g}^{-1}$, as shown in Fig. 10c, HMC-60-3d(900) electrode retains up to 99.1\% of its initial specific capacitance value.

Fig. 11 displays the EIS spectra for the carbon electrodes. The Nyquist plots of the NOMCs consist of a small semicircle at high frequency, a line with a slope close to $45^{\circ}$ within the middle frequency, and almost vertical line at low frequency. The intercept $Z$-real at very high frequency corresponds to the electric series resistance (ESR). ${ }^{38}$ All the samples show comparable ESR of 0.13-0.21 $\Omega$. The low ESR indicates the higher electrical conductivity of the carbon electrodes. The diameter of the semicircle on the $Z^{\prime}$ axis in the high frequency region referred to the polarisation resistance $\left(R_{\mathrm{p}}\right)$ is associated with the surface properties of the porous electrode, corresponding to the interfacial faradic charge transfer resistance. No semicircle was 


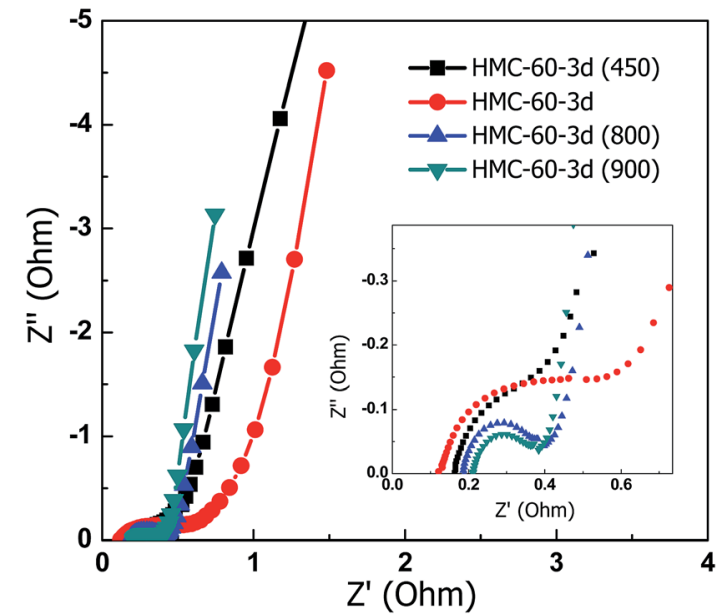

Fig. 11 Nyquists plot of the NOMCs carbonized at different temperatures. The inset shows the enlarged plot of higher frequency part.

observed for HMC-60-3d(450) and HMC-60-3d(600), indicating the lower impedance on electrode/electrolyte interface. This may be due to the hydrophilic surface by much residual functional groups on the surface of carbon electrodes obtained under lower carbonization temperatures. The $R_{\mathrm{p}}$ of HMC-60$3 \mathrm{~d}(900)$ is as low as $0.17 \Omega$. The relatively low internal resistance of HMC-60-3d(900) in $6 \mathrm{M} \mathrm{KOH}$ aqueous solution indicates the high mass transfer/diffusion rate of ions into the pores.

\section{3 $\mathrm{CO}_{2}$ capture performance}

With distinctively abundant narrow micropores and nitrogen functionality, the synthesized NOMCs have potential for applications in $\mathrm{CO}_{2}$ capture. As shown in Fig. 12, the $\mathrm{CO}_{2}$ adsorption isotherms of the NOMCs carbonized at different temperatures were collected at 0 and $25^{\circ} \mathrm{C}$. It is found that as the adsorption temperature increase from 0 to $25^{\circ} \mathrm{C}$, the $\mathrm{CO}_{2}$ capture capacity decreases. The samples carbonized at different temperatures show high $\mathrm{CO}_{2}$ capture capacity of $2.9-4.7 \mathrm{mmol} \mathrm{g}^{-1}$ at $0{ }^{\circ} \mathrm{C}$ and 1.7-3.5 $\mathrm{mmol} \mathrm{g}^{-1}$ at $25^{\circ} \mathrm{C}$, comparable with that of the reported nitrogen-containing porous carbon materials. ${ }^{39}$ Considering the relatively low content of $\mathrm{CO}_{2}$ in flue gas, the $\mathrm{CO}_{2}$ capacities at low pressure (e.g., 0.15 bar) are more valuable for the capture of $\mathrm{CO}_{2}$ from flue gas. HMC-60-3d(900) exhibits a $\mathrm{CO}_{2}$ capture capacity of $1.36 \mathrm{mmol} \mathrm{g}^{-1}$ at $0{ }^{\circ} \mathrm{C}$ and 0.15 bar, which is comparable with that of nitrogen-doped graphene-like mesomacroporous carbon with high nitrogen content of $15.7 \mathrm{wt} \%$ (1.49 $\mathrm{mmol} \mathrm{g}^{-1}$ at $0{ }^{\circ} \mathrm{C}$ and 0.15 bar). ${ }^{40}$ Furthermore, one can found that the $\mathrm{CO}_{2}$ adsorption on NOMCs is a combination effect of nitrogen functionality and porosity. For example, although HMC-60-3d and HMC-60-3d(900) have similar total nitrogen contents (1.54 vs. 1.39 at\%), the $\mathrm{CO}_{2}$ capacities of HMC-60-3d(900) (1.81 mmol g ${ }^{-1}$ at $0{ }^{\circ} \mathrm{C}$ and $0.15 \mathrm{bar} ; 1.36 \mathrm{mmol}$ $\mathrm{g}^{-1}$ at $25^{\circ} \mathrm{C}$ and 0.15 bar) are much higher than that of HMC-60$3 \mathrm{~d}\left(1.48 \mathrm{mmol} \mathrm{g}^{-1}\right.$ at $0{ }^{\circ} \mathrm{C}$ and $0.15 \mathrm{bar} ; 1.12 \mathrm{mmol} \mathrm{g}^{-1}$ at $25^{\circ} \mathrm{C}$ and 0.15 bar), which is believed to be a result of the higher surface area of HMC-60-3d(900). At 0 and $25{ }^{\circ} \mathrm{C}$ ( 1 bar), the maximum $\mathrm{CO}_{2}$ uptake of HMC-60-3d(900) is 4.7 and $3.5 \mathrm{mmol}$ $\mathrm{g}^{-1}$, respectively. The high $\mathrm{CO}_{2}$ capture capacity of HMC-60$3 \mathrm{~d}(900)$ is comparable with that of the nitride OMCs (3.46 mmol g ${ }^{-1}$ at $\left.25{ }^{\circ} \mathrm{C}\right),{ }^{8}$ much higher than that of softtemplated OMCs $\left(2.73 \mathrm{mmol} \mathrm{g}^{-1}\right.$ at $\left.25{ }^{\circ} \mathrm{C}\right),{ }^{41}$ the nitrogen and magnesium codoped mesoporous carbon composites $\left(2.26 \mathrm{mmol} \mathrm{g}^{-1} \text { at } 25^{\circ} \mathrm{C}\right)^{42}$ and the hollow carbon spheres with high nitrogen content of $14.8 \%\left(2.67 \mathrm{mmol} \mathrm{g}{ }^{-1}\right.$ at $\left.25^{\circ} \mathrm{C}\right) .^{43}$ It is clear that the prepared carbon materials by this simple LTA method achieve an excellent adsorption capacity for $\mathrm{CO}_{2}$ capture. This promising $\mathrm{CO}_{2}$ capture performance for NOMCs in our case can be attributed to the high surface area, large amounts of micropores and the nitrogen functional groups.

As discussed above, the increased $\mathrm{CO}_{2}$ capture capacities are clearly revealed with elevating carbonization temperature. However, previous studies demonstrated that the adsorption capacity decreased with the increase of carbonization temperature due to the reducing surface basic nitrogen functional groups and slight enhancement of the textural properties. ${ }^{39}$ In order to determine the influence of both textural and surface chemistry properties on the performance of the obtained NOMCs, the $\mathrm{CO}_{2}$ capture capacities are corrected according to the pore volume $\left(V_{\text {Total }}\right)$, narrow micropore volume $\left(W_{0}\right)$ and nitrogen content, ${ }^{\mathbf{4 4 , 4 5}}$ as listed in Table 2. Normalisation of $\mathrm{CO}_{2}$
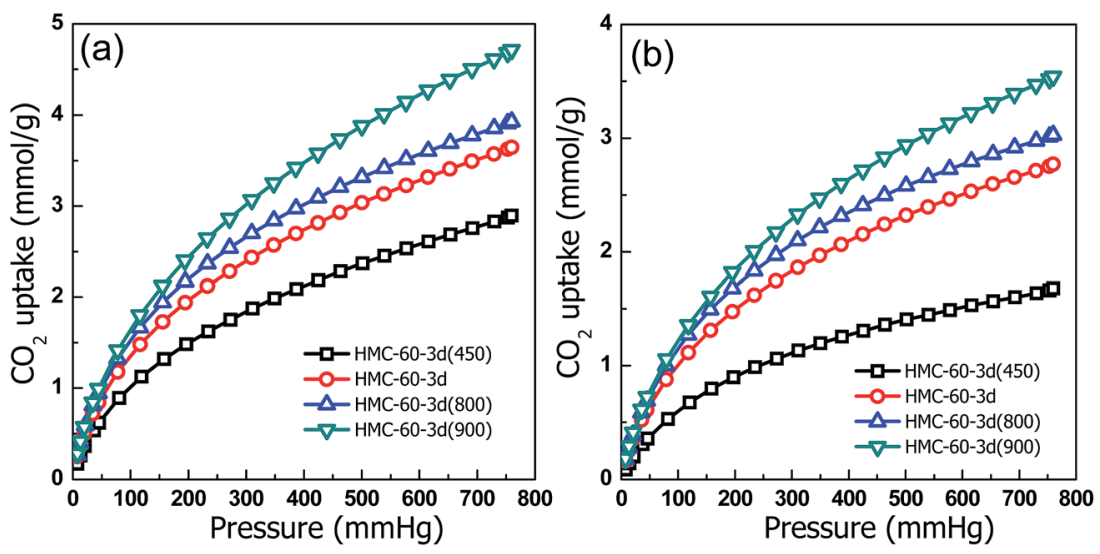

Fig. $12 \mathrm{CO}_{2}$ adsorption isotherms of NOMCs at (a) $0^{\circ} \mathrm{C}$ and (b) $25^{\circ} \mathrm{C}$. 
Table $2 \mathrm{CO}_{2}$ adsorption capacities of the prepared adsorbents at $25^{\circ} \mathrm{C}$, normalized by pore volume, narrow micropore volume and nitrogen content

\begin{tabular}{|c|c|c|c|}
\hline \multirow[b]{2}{*}{ Sample } & \multicolumn{3}{|c|}{ Normalized $\mathrm{CO}_{2}$ capture capacities at $25^{\circ} \mathrm{C}$} \\
\hline & $\begin{array}{l}V_{\mathrm{p}} \\
\left(\mathrm{mmol} \mathrm{CO} \mathrm{Cl}_{2} \text { per } \mathrm{cm}^{3}\right)\end{array}$ & $\begin{array}{l}W_{0} \\
\left(\mathrm{mmol} \mathrm{CO} \mathrm{Co}_{2} \text { per } \mathrm{cm}^{3}\right)\end{array}$ & $\begin{array}{l}\mathrm{N} \text { content }(\mathrm{mmol} \\
\left.\mathrm{CO}_{2} \text { per } \mathrm{mmol} \mathrm{N}\right)\end{array}$ \\
\hline HMC-60-3d & 8.92 & 4.82 & 2.71 \\
\hline HMC-60-3d(800) & 9.21 & 5.15 & 2.02 \\
\hline HMC-60-3d(900) & 8.43 & 5.01 & 3.22 \\
\hline
\end{tabular}

capacities by the total pore volume (Table 2) reflects the influence of surface chemistry properties on the $\mathrm{CO}_{2}$ uptake, while normalisation of the capture capacities by the narrow micropore volume (Table 2) reveals the effect of mesoporosity and wide microporosity together with surface chemistry properties of the samples on the $\mathrm{CO}_{2}$ uptake. ${ }^{45}$ The sample HMC-60$3 \mathrm{~d}(900)$ generated at $900{ }^{\circ} \mathrm{C}$ exhibits the lowest capture capacities per total pore volume at $25{ }^{\circ} \mathrm{C}$, although possessing the greatest textural development in terms of total pore and micropore volumes. This indicates that higher carbonization temperature has a negative effect on the chemistry properties of the adsorbent as it reduces the chemical affinity towards $\mathrm{CO}_{2}$ capture $^{39}$ The nitrogen-doped carbons treated at low carbonization temperature (HMC-60-3d(600) and HMC-60-3d(800)) exhibit greater capacities per total pore and narrow micropore volume than that of high temperature treated samples (HMC$60-3 \mathrm{~d}(900))$, indicating the chemistry properties of the samples favor the $\mathrm{CO}_{2}$ adsorption at low temperature $\left(<800^{\circ} \mathrm{C}\right)$, although their microporosity is not well developed.

Normalization of $\mathrm{CO}_{2}$ capture capacities by the nitrogen content of the samples was also performed to isolate the effect of the texture on the $\mathrm{CO}_{2}$ uptake (Table 2). The samples with the largest micropore volumes (HMC-60-3d(900)) show the highest $\mathrm{CO}_{2}$ uptakes per mmol of $\mathrm{N}$, indicating that the $\mathrm{CO}_{2}$ capture capacities of HMC-60-3d(900) were mainly physical adsorption. ${ }^{44}$ The discussion above reveals that the $\mathrm{CO}_{2}$ capture behavior of all the NOMCs is a combination of physical adsorption and chemical sorption, but not making an equal

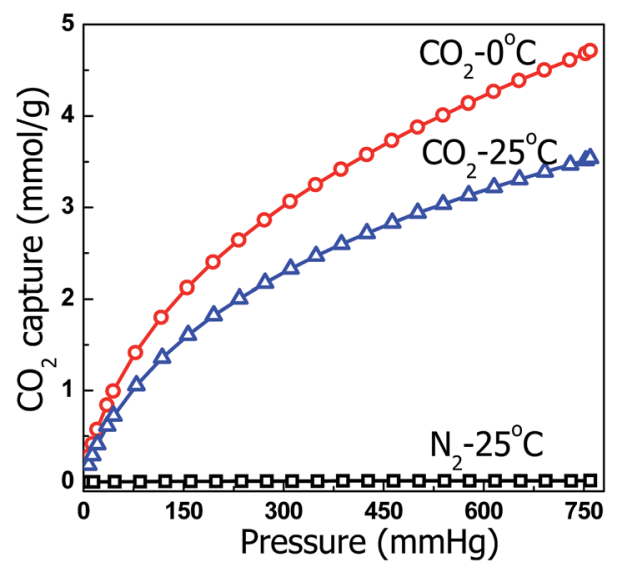

Fig. $13 \mathrm{CO}_{2}$ and $\mathrm{N}_{2}$ sorption isotherms of $\mathrm{HMC}-60-3 \mathrm{~d}(900)$. contribution. The $\mathrm{CO}_{2}$ capture capacities of HMC-60-3d and HMC-60-3d(800) carbons are strongly dominated by the surface chemistry properties. The $\mathrm{CO}_{2}$ uptake of HMC-60-3d(900) is mainly influenced by the adsorption on the narrow micropores, less controlled by the surface chemistry properties of the adsorbents, most probably due to less affinity to $\mathrm{CO}_{2}$ of the nitrogen functionalities present in these samples.

For practical applications, proper adsorbents must possess a high selectivity against other gases in addition to high $\mathrm{CO}_{2}$ capture capacity. The $\mathrm{CO}_{2}$ separation performance of the selected samples was evaluated. Fig. 13 shows the $\mathrm{N}_{2}$ adsorption isotherms of HMC-60-3d(900) at $25^{\circ} \mathrm{C}$ and $1 \mathrm{bar}$, in comparison with their $\mathrm{CO}_{2}$ adsorption isotherms. HMC-60-3d(900) exhibits $\mathrm{N}_{2}$ adsorption capacity of only $0.26 \mathrm{mmol} \mathrm{g}^{-1}$ at ambient pressure, which is less than one tenth of the amount of $\mathrm{CO}_{2}$, suggesting that HMC-60-3d(900) could also be a potential selective adsorbent for $\mathrm{CO}_{2}$ adsorption.

\section{Conclusions}

The LTA route is demonstrated to be a facile, cost-effective and readily reproducible synthetic approach for the preparation of NOMCs with $\operatorname{Im} \overline{3} m$ cubic structure at low-temperature of $60{ }^{\circ} \mathrm{C}$. Resorcinol and HMT are employed as carbon precursor and triblock copolymer F127 as template under basic conditions. The autoclaving time $\geq 2 \mathrm{~d}$ are favorable for the formation of highly ordered $\operatorname{Im} \overline{3} m$ mesostructure at autoclaving temperature of $60^{\circ} \mathrm{C}$. These NOMCs possess a moderate amount of nitrogen (1.39-2.1 at\%), a large fraction of fine micropores, high surface area and uninterrupted mesopores, leading to high capacitance $\left(193 \mathrm{~F} \mathrm{~g}^{-1}\right.$ at $\left.1.0 \mathrm{~A} \mathrm{~g}^{-1}\right)$, excellent rate capability $\left(174 \mathrm{~F} \mathrm{~g}^{-1}\right.$ at 10 $\mathrm{A} \mathrm{g}^{-1}$ ), outstanding cycling stability ( $99.1 \%$ capacity retention after 500 cycles at $1.0 \mathrm{~A} \mathrm{~g}^{-1}$ ) and high $\mathrm{CO}_{2}$ adsorption capacities ( $3.5 \mathrm{mmol} \mathrm{g}^{-1}$, at $25^{\circ} \mathrm{C}$ and $780 \mathrm{~mm} \mathrm{Hg}$ ). The assemblies of the resin and the surfactant in the solution under autoclaving conditions may be useful for the large-scale industrial production of NOMCs materials.

\section{Acknowledgements}

This work was supported by the National Natural Science Foundation of China (No. 51302154, 51402160 and 21573115), Natural Science Foundation of Shandong Province, China (BS2013CL032 and ZR2014EMQ011), and the SDUST Research Fund (2015YQJH101). 


\section{References}

1 J. Tang, J. Liu, C. L. Li, Y. Q. Li, M. O. Tade, S. Dai and Y. Yamauchi, Angew. Chem., Int. Ed., 2015, 54, 588-593.

2 J. Xu, A. Wang and T. Zhang, Carbon, 2012, 50, 1807-1816.

3 L. Liu, F. Y. Wang, G. S. Shao and Z. Y. Yuan, Carbon, 2010, 48, 2660-2664.

4 X. Q. Wang, C. D. Liang and S. Dai, Langmuir, 2008, 24, 75007508.

5 C. Liang and S. Dai, J. Am. Chem. Soc., 2006, 128, 5316-5317.

6 L. Liu, F. Y. Wang, G. S. Shao and Z. Y. Yuan, Carbon, 2010, 48, 2089-2099.

7 F. Zhang, Y. Meng, D. Gu, Y. Yan, C. Yu, B. Tu and D. Zhao, J. Am. Chem. Soc., 2005, 127, 13508-13509.

8 L. Liu, Q. F. Deng, T. Y. Ma, X. Z. Lin, X. X. Hou, Y. P. Liu and Z. Y. Yuan, J. Mater. Chem., 2011, 21, 16001-16009.

9 G. P. Hao, W. C. Li, S. Wang, G. H. Wang, L. Qi and A. H. Lu, Carbon, 2011, 49, 3762-3772.

10 A. H. Lu, B. Spliethoff and F. Schüth, Chem. Mater., 2008, 20, 5314-5319.

11 Y. P. Zhu, Y. L. Liu, Y. P. Liu, T. Z. Ren, T. H. Chen and Z. Y. Yuan, ChemCatChem, 2015, 7, 2903-2909.

12 D. Liu, J. H. Lei, L. P. Guo, D. Y. Qu, Y. Li and B. L. Su, Carbon, 2012, 50, 476-487.

13 Y. P. Zhu, Y. P. Liu and Z. Y. Yuan, Chem. Commun., 2016, 52, 2118-2121.

14 D. Liu, J. H. Lei, L. P. Guo and K. J. Deng, Carbon, 2011, 49, 2113-2119.

15 M. Chen, L. L. Shao, Y. P. Liu, T. Z. Ren and Z. Y. Yuan, J. Power Sources, 2015, 283, 305-313.

16 K. Ai, Y. L. Liu, C. P. Ruan, L. H. Lu and G. Q. Lu, Adv. Mater., 2013, 25, 998-1003.

17 Y. Fang, D. Gu, Y. Zou, Z. X. Wu, F. Y. Li, R. C. Che, Y. H. Deng, B. Tu and D. Y. Zhao, Angew. Chem., Int. Ed., 2010, 49, 7987-7991.

18 C. Wang, L. Sun, Y. Zhou, P. Wan, X. Zhang and J. Qiu, Carbon, 2013, 59, 537-546.

19 X. Yan, Y. Liu, X. Fan, X. Jia, Y. Yu and X. Yang, J. Power Sources, 2014, 248, 745-751.

20 L. Sun, C. Tian, Y. Fu, Y. Yang, J. Yin, L. Wang and H. Fu, Chem.-Eur. J., 2014, 20, 564-574.

21 C. H. Choi, S. H. Park, M. W. Chung and S. I. Woo, Carbon, 2013, 55, 98-107.

22 S. Yin and T. Sato, J. Mater. Chem. A, 2015, 15, 4584-4587.

23 D. Y. Zhao, Q. S. Huo, J. L. Feng, B. F. Chmelka and G. D. Stucky, J. Am. Chem. Soc., 1998, 120, 6024-6036.

24 J. R. Matos, M. Kruk, L. P. Mercuri, M. Jaroniec, L. Zhao, T. Kamiyama, O. Terasaki, T. J. Pinnavaia and Y. Liu, J. Am. Chem. Soc., 2003, 125, 821-829.
25 J. R. Matos, M. Kruk, L. P. Mercuri, M. Jaroniec, T. Asefa, N. Coombs, G. A. Ozin, T. Kamiyama and O. Terasaki, Chem. Mater., 2002, 14, 1903-1905.

26 J. Yu, M. Guo, F. Muhammad, A. Wang, F. Zhang, Q. Li and G. Zhu, Carbon, 2014, 69, 502-514.

27 X. Q. Wang, C. G. Liu, D. Neff, P. F. Fulvio, R. T. Mayes, A. Zhamu, Q. Fang, G. R. Chen, H. M. Meyer, B. Z. Jang and S. Dai, J. Mater. Chem. A, 2013, 1, 7920-7926.

28 G. Z. Shen, X. R. Sun, H. W. Zhang, Y. Liu, J. Zhang, A. Meka, L. Zhou and C. Z. Yu, J. Mater. Chem. A, 2015, 3, 2404124048.

29 J. Wei, D. D. Zhou, Z. K. Sun, Y. H. Deng, Y. Y. Xia and D. Y. Zhao, Adv. Funct. Mater., 2013, 23, 2322-2328.

30 Q. Shi, R. Y. Zhang, Y. Y. Lu, Y. H. Deng, A. A. Elzatahrya and D. Y. Zhao, Carbon, 2015, 84, 335-346.

31 C. Q. Yuan, X. H. Liu, M. Y. Jia, Z. X. Luo and J. N. Yao, J. Mater. Chem. A, 2015, 3, 3409-3415.

32 C. Liu, J. Wang, J. Li, X. Hu, P. Lin, J. Shen, X. Sun, W. Han and L. Wang, J. Mater. Chem. A, 2016, 4, 11916-11923.

33 T. Y. Yang, R. F. Zhou, D. W. Wang, S. P. Jiang, Y. Yamauch, S. Z. Qiao, M. J. Monteiro and J. Liu, Chem. Commun., 2015, 51, 2518-2521.

34 H. H. Xu, X. L. Hu, Y. M. Sun, H. L. Yang, X. X. Liu and Y. H. Huang, Nano Res., 2015, 8, 1148-1158.

35 X. M. Ma, L. H. Gan, M. X. Liu, P. K. Tripathi, Y. H. Zhao, Z. J. Xu, D. Z. Zhu and L. W. Chen, J. Mater. Chem. A, 2014, 2, 8407-8415.

36 M. X. Liu, J. S. Qian, Y. H. Zhao, D. Z. Zhu, L. H. Gan and L. W. Chen, J. Mater. Chem. A, 2015, 3, 11517-11526.

37 N. P. Wickramaratne, J. T. Xu, M. Wang, L. Zhu, L. M. Dai and M. Jaroniec, Chem. Mater., 2014, 26, 2820-2828.

38 T. Z. Ren, L. Liu, Y. Y. Zhang and Z. Y. Yuan, J. Solid State Electrochem., 2013, 17, 927-935.

39 G. P. Hao, W. C. Li, D. Qian and A. H. Lu, Adv. Mater., 2010, 22, 853-857.

40 F. Liu, K. Huang, S. Ding and S. Dai, J. Mater. Chem. A, 2016, 4, 14567-14571.

41 Z. Z. Zhang, B. D. Wang, C. M. Zhu, P. Gao, Z. Y. Tang, N. N. Sun, W. Wei and Y. H. Sun, J. Mater. Chem. A, 2015, 3, 23990-23999.

42 Z. Z. Zhang, C. M. Zhu, N. N. Sun, H. Wang, Z. Y. Tang, W. Wei and Y. H. Sun, J. Phys. Chem. C, 2015, 119, 93029310.

43 S. S. Feng, W. Li, Q. Shi, Y. H. Li, J. C. Chen, Y. Ling, A. M. Asiri and D. Y. Zhao, Chem. Commun., 2014, 50, 329-331.

44 L. Liu, Q. F. Deng, X. X. Hou and Z. Y. Yuan, J. Mater. Chem., 2012, 22, 15540-15548.

45 C. Pevida, T. C. Drage and C. E. Snape, Carbon, 2008, 46, 1464-1474. 